\title{
O SAGRADO E O PROFANO NAS ORGANIZAÇÕES CONTEMPORÂNEAS
}

THE SACRED AND PROFANE IN CONTEMPORARY ORGANIZATIONS

Alessandro Gomes Enoque*

Doutor em Ciências Humanas (Sociologia e Ciência Política) pela Universidade Federal de Minas Gerais (UFMG). Mestre em Administração pela Universidade Federal de Minas Gerais (UFMG). Atualmente, é professor adjunto da Universidade Federal de Uberlândia (UFU)

Uberlândia, MG, Brasil

E-mail: alessandroenoque@pontal.ufu.br

Alex Fernando Borges

Doutorando em Administração - Programa de Pós-Graduação em Administração da Universidade Federal de Lavras (PPGA-UFLA). Mestre em Administração - Programa de Pós-Graduação em Administração,

Universidade Federal de Lavras (PPGA-UFLA). Professor Assistente da Universidade Federal de Uberlândia (UFU) - Faculdade de Ciências Integradas do Pontal (FACIP)

Uberlândia, MG, Brasil

E-mail: alexfborges@gmail.com

Jacquelaine Florindo Borges

Doutora em Administração - Programa de Pós-Graduação em Administração da Universidade de São Paulo (USP). Mestre em Administração pela Faculdade de Gestão e Negócios (FAGEN) da Universidade Federal de Uberlândia (UFU). Professora Adjunta da Universidade Federal de Uberlândia (UFU) - Faculdade de Gestão e Negócios (FAGEN)

Uberlândia, MG, Brasil

E-mail: jac.borges@uol.com.br

\section{RESUMO}

É fato comumente aceito nos estudos sobre religião que as categorias do sagrado e do profano se constituem como elementos centrais na compreensão acerca das modalidades de existência do homem no mundo (TEIXEIRA, 2010; BERGER, 2004; ELIADE, $2002,2008)$. Ao lançarmos nossos olhos para a área de estudos organizacionais, percebemos que tais conceitos, no entanto, são parcamente trabalhados pelos autores. É objetivo deste ensaio teórico, portanto, compreender algumas das possibilidades de interlocução entre os conceitos de sagrado e profano, especialmente no que tange as suas dimensões espacial e temporal, no universo das organizações e à luz das importantes contribuições de Eliade (2002, 2008).

Palavras-chave: Sagrado. Profano. Capitalismo. Religião. Organizações.

Data de submissão: 25 de novembro de 2014.

\section{ABSTRACT}

It is commonly accepted fact in studies of religion that the categories of the sacred and the profane are formed as key elements in understanding the existence of man modalities in the world (TEIXEIRA, 2010; BERGER, 2004; ELIADE, 2002; ELIADE, 2008). As we shed lights on the organizational studies field, we realized that the authors, however, poorly study such concepts. Hence, the purpose of this theoretical essay is to understand some of the possibilities of dialogue between the sacred and profane concepts, especially regarding their spatial and temporal dimensions in organizations, inspired in the important contributions of Eliade $(2002,2008)$

Keywords: Sacred. Profane. Capitalism. Religion. Organization.

Data de aprovação: 30 de julho de 2015. 


\section{INTRODUÇÃO}

É fato comumente aceito nos estudos de antropologia, história e sociologia da religião, que as categorias do sagrado e do profano se constituem como elementos centrais na compreensão acerca das modalidades de existência do homem no mundo (DURKHEIM, 1996; WEBER, 2000, 2001, 2006; BOURDIEU, 2005, 2007, 2008, 2010; TEIXEIRA, 2010; BERGER, 2004; ELIADE, 2002, 2008). A relação de tais conceitos, especialmente no que se refere a suas imbricações com as dimensões espacial e temporal, revela um amplo leque de possibilidades de investigação, que ultrapassa o espectro das disciplinas acima mencionadas e passa a ser objeto de interesse de qualquer investigador desejoso de conhecer a complexidade da existência humana em sociedade.

Ao lançarmos nossos olhos para a área de estudos organizacionais, percebemos que tais conceitos (o sagrado e o profano) são parcamente trabalhados pelos autores (DODD; GOTSIS, 2007; TRACEY, 2012; ASHFORTH; VAIDYANATH, 2002; KAMOCHE, 2000; TRACEY; PHILLIPS; LOUNSBURY, 2014). Tracey (2012) argumenta, ainda, que os debates que tem por objeto a interlocução entre os universos religioso e organizacional não estão presentes nos principais periódicos da área de estudos organizacionais. Em sua rica revisão da literatura sobre o tema, o autor identificou apenas oitenta e seis artigos relacionados ao tópico religião nos vinte e um principais periódicos da área de estudos organizacionais, no período de 1950 a 2011. Tal realidade poderia ser explicada, potencialmente, a um certo 'incômodo' que as iniciativas de apropriação de temáticas do universo religioso em um espaço 'pretensamente' laico, como é o caso das organizações empresariais, gerariam no âmbito da academia e nos próprios pesquisadores. Tracey, Phillips e Lounbury (2014) reforçam tal entendimento, ao identificarem como barreiras para o engajamento dos pesquisadores no tema, dentre outras questões, a aparente crença (equivocada, ao nosso ver) de que a religião não seria um objeto apropriado de estudo científico para área de estudos organizacionais.

Além disto, há que se destacar, que a pretensa laicidade empresarial configura-se, em nosso entender, como um mito, que obscurece outras possibilidades alternativas de compreender o universo empresarial. Tal mito, disseminado e propagado através de um discurso que privilegia uma racionalidade de natureza instrumental/técnica, pode ser inicialmente descontruído, na medida em que observemos qualquer indivíduo que trabalhe em uma organização moderna. Suas angústias, alegrias, desilusões, indecisões, entre outros tantos exemplos, são permeados por pequenos gestos e rituais que demonstram, claramente, que a faceta do 'homo religiosus' está intrinsecamente relacionada ao 'homo organizacional' e vice-versa. $\mathrm{Na}$ realidade, tais facetas do homem moderno não podem ser simplesmente separadas no plano social a não ser por uma compreensão limitada da existência humana em sociedade. A pretensa laicidade empresarial configura-se, ainda, enquanto mito, na medida em que compreendemos que os conceitos de sagrado e profano, especialmente no que tange as suas interlocuções com a temporalidade e a espacialidade, são anteriores ao aparecimento de qualquer organização empresarial. Na realidade, os referidos conceitos são tão primitivos que se constituem enquanto objeto privilegiado de estudo de historiadores de religiões primitivas e estão intrinsecamente ligados a relação do homem com o plano social.

Podemos constatar, ainda, que a existência mais dessacralizada a qual o homem tenha chegado não consegue abolir, completamente, o comportamento religioso e que, mesmo o universo mais dessacralizado, conserva pequenos traços de valorização religiosa. Neste sentido, Ashforth e Vaidyanath (2002) argumentam 
que, no âmbito das organizações empresariais, a religião seria muito mais que uma simples metáfora. Ao contrário, seria, sim, uma descrição literal da vida, na medida em que edificaria verdadeiras cosmologias e encorajaria fé em missões transcendentes.

Diante do exposto, é objetivo deste ensaio teórico compreender algumas das possibilidades de interlocução entre os conceitos do sagrado e do profano, especialmente no que tange as suas dimensões espacial e temporal, no universo das organizações empresariais modernas à luz das importantes contribuições de Eliade $(2002,2008)$. É evidente que, pela amplitude do tema e pela limitação de nossa capacidade, será necessário trabalhar alguns pontos específicos e deixar outros de lado. Esperamos que, apesar de tais limitações, o presente ensaio possa lançar luzes sobre novas possibilidades de análise na área de estudos organizacionais.

Este artigo está estruturado nas seguintes seções, além desta introdução: os espaços sagrado e profano; os tempos sagrado e profano; o sagrado, o profano, o espaço e o tempo: diálogos possíveis; considerações finais; e referências.

\section{OS ESPAÇOS SAGRADO E PROFANO}

Eliade (2008), em seus estudos acerca da história das religiões, argumenta que a compreensão dos conceitos de sagrado e profano somente pode ser apreendida em uma perspectiva puramente relacional. Nesse sentido, tais dimensões se comportariam como faces diferentes, porém interdependentes, de uma mesma moeda, que se auto-influenciariam, especificamente, em dois temas principais: o espaço e o tempo.

No que tange ao espaço, objeto desta seção, inicialmente podemos argumentar que, ao contrário do que normalmente pensamos, o mesmo não pode ser compreendido como sendo uma massa total amorfa e homogênea. Pelo contrário, de acordo com Eliade (2008), para o homem religioso o mesmo constituir-se-ia enquanto não-homogêneo, apresentando rupturas e quebras, configurando porções qualitativamente diferentes das outras. Haveria, portanto, um espaço caracterizado enquanto sagrado ("forte", "significativo") e outro não-sagrado/profano ("sem estrutura", "sem consistência"). Há, ainda, implícito na afirmação acima, a ideia de que o espaço sagrado é carregado de uma positividade inerente que se encontra ausente no universo profano. Tal positividade, gerada a partir de uma hierofania, implicaria em uma consequente hierarquização dos espaços sociais.

Tal constatação pode ser observada tanto em uma perspectiva macro (em uma cidade, por exemplo), quanto em uma perspectiva micro (interior de uma empresa). Ao observarmos uma pequena cidade do interior brasileiro, podemos notar, por exemplo, tal distribuição espacial do sagrado em contraposição ao profano. Normalmente localizada no centro da cidade, a igreja funda-se enquanto lócus do sagrado em contraposição ao restante da rua (do espaço público) destinado ao comércio e as "coisas do mundo". Sua posição central no plano da cidade resgata, simbolicamente, a importância da instituição igreja na vida cotidiana dos habitantes daquela cidade no momento em que a mesma foi construída. Cabe destacar, aqui, a força do simbolismo do centro nas diversas religiões ocidentais e orientais. Para Eliade (2002, p. 34),

[...] as sociedades arcaicas e tradicionais concebiam o mundo que a cerca como um microcosmo. Nos limites desse mundo fechado começa o domínio do desconhecido, do não-formado. De um lado, existe um espaço cosmicizado, uma vez que habitado e organizado. Do outro lado, fora desse espaço familiar, existe a 
região desconhecida e temível dos demônios, das larvas, dos mortos, dos estranhos - ou seja, o caos, a morte, a noite (ELIADE, 2002, p. 34).

A posição central da igreja não se limita, no entanto, somente a separação entre o mundo sagrado (no interior da construção) e o profano (no exterior da construção). A igreja encontra-se, também, simbolicamente representada como sendo o centro de três universos distintos: o inferno, a terra (onde está localizada a igreja) e o céu. Simbolicamente, estas três regiões são interligadas através da torre ou, em outras culturas, através da árvore, do totem, da montanha ou da pilastra.

Cumpre ressaltar, aqui, que, além desta centralidade atribuída a igreja nos dois diferentes argumentos apontados acima, podemos observar também que, normalmente, tais edificações apresentam-se bastante altas, sendo necessário ao transeunte a elevação de sua cabeça para contemplá-las totalmente. Tal posição contemplativa e, por que não dizer, submissa, revela, simbolicamente, algo do universo sagrado, que não pode ser atingido a não ser a custa de muito esforço. É neste sentido que a figura da escada é tão presente tanto na mitologia religiosa quanto nas próprias construções dos templos.

Convêm destacar que a passagem do espaço sagrado para o profano é intermediada, simbolicamente, pela figura da porta. Tal símbolo materializaria, de alguma forma, a descontinuidade presente entre os dois espaços, delimitando a fronteira/limiar destes dois mundos. A porta seria, por assim dizer, um veículo de passagem para o indivíduo que anseia transitar do espaço profano para o sagrado, com o objetivo de irromper-se em um território cósmico que o envolve e o torna qualitativamente diferente. Esta passagem seria acompanhada, no entanto, por uma série de pequenos ritos, prosternações, preces, que legitimariam, por assim dizer, a entrada do fiel em um espaço qualitativamente diferente (superior, positivo) no comparativo com a rua. É dentro desta perspectiva que observamos uma série de fiéis que adentram as igrejas católicas brasileiras e, prontamente, fazem o sinal da cruz em reverência a Deus ou utilizam-se da água benta e fazem uma cruz em suas testas. A compreensão de que este espaço sagrado é "diferente" do que está do lado de "fora" traduz-se, também, nos pequenos gestos de silêncio e contemplação aos santos.

Há, além disto, uma tentativa de proteger este espaço sagrado, fundado em repetição ao ato cosmogônico, da influência e dos ataques do mundo exterior (profano). Dito de outra forma, a entrada de uma lógica profana no espaço do sagrado traria consigo uma desordem que culminaria no Caos.

É possível imaginar, no entanto, que estes espaços sociais são continuamente significados e ressignificados por seus visitantes ao longo da história. Nesse sentido, os diversos símbolos presentes nestes espaços, bem como as liturgias associadas aos mesmos, além do próprio sentido atribuído ao local, mudam constantemente tornando-os mais ou menos sagrados (exemplo: mercado do turismo religioso em igrejas antigas). Maia e Lattanzi (2007) nos mostram que a compreensão do termo lugar remeteria à ideia de uma edificação desse espaço, alicerçado no plano do vivido, mediado pelas relações sociais e, assim, funcionaria como pilar de significados, de afetos, de sentidos que permitiriam ao indivíduo estabelecer relações diversas com ele, definindo-o como um ambiente de comunhão, centro de apoio, de referências sociais e culturais, de ação, consolidado a partir das experiências cotidianas compartilhadas. Desta maneira, os diversos indivíduos criariam símbolos e significados que contribuiriam para urdir o próprio sentido de lugar. Em uma perspectiva complementar, Certeau (2001) nos mostra que a diferença que definiria todo lugar não seria a da ordem de uma justaposição, mas teria a forma de estratos imbricados. 
Perniola (1997) insere-se, no interior desta dicotomia do espaço do sagrado e do profano, através de duas categorias interessantes: o mais-que-sagrado e o mais-que-profano. De acordo com o autor, uma vez que tais categorias nascem no universo do cotidiano, seriam nesses ambientes que os sujeitos teriam capacidade de se movimentar. Em outros termos, os sujeitos vislumbrariam, em seu cotidiano, o profano como parte do sagrado e vice-versa, transgredindo as regras e convenções sociais. Cabe destacar este último ponto, na medida em que vemos, no dia-a-dia, diversas constatações de transposição do sagrado para o profano (a utilização de nomes de santos em lojas comerciais, a utilização de símbolos religiosos no espaço do trabalho, a realização de preces e rezas no início do trabalho, etc.) e do profano para o sagrado (utilização de práticas gerenciais em igrejas, utilização de estratégias de marketing para atração de novos fiéis, etc.).

A seção seguinte terá, por objeto, a análise do conceito de tempo à luz das dimensões do sagrado e do profano.

\section{OS TEMPOS SAGRADO E PROFANO}

Conforme Eliade (2008), da mesma forma que o espaço não pode ser compreendido enquanto homogêneo, nem contínuo, o tempo apresenta-se, também, estratificado nas dimensões do sagrado e do profano. Haveria, por assim dizer, intervalos de tempo sagrado, quais sejam, aqueles relacionados ao tempo das festas (em sua maioria, festas periódicas) podendo ser caracterizados como tendo caráter circular, reversível, recuperável, "[...] espécie de eterno presente mítico que o homem reintegra periodicamente pela linguagem dos ritos" (ELIADE, 2008, p. 64), bem como o tempo profano, compreendido enquanto "[...] duração temporal ordinária na qual se inscrevem os atos privados de significado religioso" (ELIADE, 2008, p. 63). Ainda de acordo com o autor, entre estas duas espécies de tempo, existiria uma solução de continuidade, mas, por meio de ritos, o homem poderia passar de uma duração temporal ordinária para o tempo do sagrado.

Esta fratura na dimensão temporal seria suficiente para distinguir o homem religioso daquele nãoreligioso. No que diz respeito ao primeiro, o mesmo vivencia os dois universos temporais privilegiando, no entanto, o momento do sagrado. É claro, portanto, que o homem religioso, em seus serviços diários, impregna-se das atividades do cotidiano. Cotidiano este sufocado por uma lógica temporal profana guiada, normalmente, pelo "tic-tac" dos relógios. Mas ele anseia, antes de tudo, retornar ao tempo sagrado/litúrgico que representaria a reatualização de um evento sagrado que teve lugar num passado mítico (ex.: a celebração da liturgia). Esta retomada de um passado mítico, para o homem religioso, insere-se, especialmente, no momento das festas litúrgicas, onde o tempo profano é rompido e o tempo sagrado recuperado.

[...] participar religiosamente de uma festa implica a saída da duração temporal ordinária e a reintegração no Tempo mítico reatualizado pela própria festa. Por conseqüência, o Tempo sagrado é indefinidamente recuperável, indefinidamente repetível (ELIADE, 2008, p. 64).

Para o homem não-religioso, há, também, uma constatação de uma certa descontinuidade e heterogeneidade do tempo. Embora grande parte do tempo do mesmo esteja relacionado, exatamente, a um existir predominantemente monótono, ligado essencialmente ao trabalho (ex.: acordar cedo, pegar o ônibus, viajar para o trabalho, trabalhar, almoçar, trabalhar novamente, retornar para casa, etc.), há espaço para momentos 'festivos' em que a lógica do lazer e dos espetáculos se insere (ex.: finais de semana, feriados, 
carnaval, etc.). Convêm destacar, como observaremos mais tarde, que, no âmbito da organização capitalista, as empresas, concebidas enquanto 'máquinas de trabalhar' tornariam profano um tempo que é sagrado ao seu trabalhador e, por que não dizer, dessacralizariam seus corpos. O tique-taque ordinário dos relógios de ponto, associado ao ritmo frenético das linhas de montagem, tornariam, para o trabalhador, o transcorrer do tempo um elemento de sofrimento. Na verdade, seria no lazer de seu mundo profano, ocorrido principalmente nos finais de semana, que o trabalhador tornar-se-ia humano.

Cumpre destacar, ainda, que, em semelhança ao ato de fundação do espaço (que possui caráter cosmogônico), o mesmo ocorre no que tange a dimensão temporal. Para Eliade (2008, p. 69), por exemplo, "[...] a cosmogonia comporta igualmente a criação do tempo. [...] toda criação é imaginada como tendo ocorrido no começo do tempo, in principio". Assim, o tempo original seria continuamente fundado e refundado no universo das festas religiosas como lócus de retomada do mundo do sagrado.

É importante notar, ainda, que o comportamento humano no antes, no durante e no depois da festa traduz, em grande parte, os sentidos que os indivíduos dão aqueles momentos históricos específicos. É neste ponto que retomamos Callois (1989), ao afirmar que a festa seria um acontecimento que não envolveria somente uma ruptura com o cotidiano, mas, também, um período de excessos, de extrapolação dos padrões sociais e de transgressão. Em uma perspectiva complementar, Duvignaud (1983) aponta que a festa não seria simples ilustração ou representação. Seria, antes de tudo, um 'espetáculo' que manteria aflorado seu universo simbólico e ritualístico, não sendo, simplesmente, mera encenação do passado. A festa poderia, ainda, adquirir a função questionadora do social, da própria cultura e do próprio cotidiano.

Esta retomada do divino não se faz, no entanto, unicamente no universo das festas. Pode-se notar, ainda, tal retomada com o sagrado nos pequenos gestos, ritos e rituais. Como exemplo de tal realidade, podemos apontar o instituto da prece, tão bem trabalhado por Marcel Mauss no texto A prece, de 1909, onde o antropólogo a traduz como um ato realizado diante das coisas sagradas, sendo o ponto de convergência de um grande número de fenômenos religiosos. Da mesma forma, contatamos o sagrado na medida em que presenciamos uma cerimônia fúnebre, onde o limiar da partida nos põe em contato com algo do divino e com uma miríade de símbolos. Lembremos, aqui, o elemento simbólico na utilização de conchas em rituais fúnebres chineses, representando um 'segundo nascimento' do indivíduo.

Convêm destacar que este arcabouço simbólico desempenharia um papel considerável na vida religiosa e não-religiosa da humanidade. De acordo com Eliade (2008), o sagrado permaneceria ativo mesmo quando retirado da vida religiosa propriamente dita, através do simbolismo. Para o autor, "[...] um símbolo religioso transmite sua mensagem mesmo quando deixa de ser compreendido, conscientemente, em sua totalidade, pois um símbolo dirige-se ao ser humano integral, e não apenas à sua inteligência" (ELIADE, 2008, p. 109). Como exemplo deste simbolismo relacionado a dimensão temporal, podemos observar o simbolismo da água, tão presente nos ritos e mitos ocidentais (batismo e dilúvio, por exemplo).

$\mathrm{Na}$ seção seguinte, as discussões realizadas acima acerca das dimensões do sagrado e do profano, especialmente no que tange a suas imbricações com os conceitos de espaço e tempo, serão confrontadas com o universo organizacional. Buscaremos, ainda, levantar algumas pontes que possam ampliar nossa visão de como tais conceitos poderiam ser apropriados pela área de estudos organizacionais. 


\section{O SAGRADO, O PROFANO, O ESPAÇO E O TEMPO: DIÁLOGOS POSSÍVEIS}

De acordo com Sanchis (2001), algo está acontecendo, contemporaneamente, nos domínios daquilo que chamamos de religião. Conforme destaca o autor, este movimento poderia resumir-se em três eixos principais: diferenciação, mundanização e racionalização/desencantamento. No que diz respeito ao primeiro (diferenciação), o fenômeno trata de uma maior autonomia das instâncias antes subsumidas à religião, como é o caso, por exemplo, do espaço familiar, bem como por uma maior especificação/distinção de seus domínios. No caso da mundanização, trata-se, fundamentalmente, de uma certa secularização interna das religiões que passaram a entrar em uma negociação mais benevolente com antigos rivais: economia, política, estética, erótica, apreensão intelectual do mundo. Por fim, temos o fenômeno da racionalização/desencantamento, amplamente tratado por Weber (2000). Neste caso, trata-se de um forte movimento presente no mundo moderno no sentido de tentar suprimir a magia e o mistério da religião (além de seus próprios conceitos) do plano social.

Para Eliade (2008), tal realidade implicaria em um processo de dessacralização das diversas experiências vitais humanas como, por exemplo: a sexualidade, a alimentação, o trabalho, entre outros. Nesse sentido, todos estes atos tornaram-se desprovidos de significado espiritual, distanciando-os de uma dimensão verdadeiramente humana. Da mesma forma, o corpo do homem moderno foi igualmente privado de todo significado religioso ou espiritual, tornando-se um 'mero equipamento carnal'.

É interessante notar, no entanto, que o homem moderno, dessacralizado e, portanto, profano, conservaria, ainda, alguns vestígios do comportamento e do pensamento do homem religioso, porém esvaziados dos significados religiosos. Dentre os espaços sociais laicos (ou pelo menos pretensamente laicos) em que tais vestígios (comportamentos e pensamentos do homem religioso) podem surgir, daremos especial destaque, a partir de agora, aquele que se tornou o centro da nossa sociedade: a empresa capitalista. Passaremos a buscar, assim, algumas interlocuções possíveis entre as dimensões do sagrado e do profano, especialmente no que tange as temáticas do espaço e do tempo (expostas nas seções anteriores), com o universo das modernas empresas capitalistas contemporâneas.

Inicialmente, podemos constatar que as empresas se tornaram o centro de nossa sociedade, assumindo um papel de destaque antes preenchido pela igreja. Nota-se, a partir daí, o surgimento de um novo sistema valorativo (de competição acirrada, busca pela sobrevivência, perseguição incansável do lucro) que suplanta uma série de preceitos religiosos, além do aparecimento de um novo 'Deus' (o capital), seus 'sacerdotes' (os gerentes), bem como os 'novos fiéis' (os clientes). Institui-se, a partir desta realidade, a noção da empresa como 'centro do nosso mundo' em contraposição ao mercado (compreendido enquanto 'local de perigos e de luta pela sobrevivência'). Esta nova ruptura no tecido espacial tornaria, nesta perspectiva, a empresa um novo locus do sagrado.

Estes homens da tecnoestrutura são os novos e universais sacerdotes. Sua religião é o sucesso nos negócios; seu teste de virtude é o crescimento e o lucro. Sua bíblia é o computador; seu banco de comunhão é a sala de reuniões. A equipe de vendas carrega sua mensagem para o mundo e a mensagem é frequentemente ouvida. [...] Os jesuítas desta fé austera são os graduados da Harvard Business School (GALBRAITH, 1977, p. 271). 
Esta realidade poderia ser vista em Pagès et al. (2008), ao mostrarem que a ideologia de natureza religiosa estaria sendo ressignificada no âmbito das empresas contemporâneas como uma forma de mascarar as relações sociais de produção e aumentar a exploração do capital sobre o trabalho de uma maneira não tão explícita. De acordo com os autores, esta 'nova dominação' buscaria o envolvimento dos funcionários através da consignação de um conjunto de valores presentes nos manuais organizacionais (as novas escrituras sagradas), bem como pela aplicação de um conjunto de práticas rituais.

Nas palavras de Ashforth e Vaidyanath (2002), este gerenciamento do simbólico incluiria o uso das declarações de missão, das estórias e mitos, das tradições e rituais, dos discursos e metáforas, bem como da construção de heróis e eventos. Para os autores, as cosmologias seriam, frequentemente, ancoradas em narrativas históricas relacionadas a visão, valores e crenças dos fundadores, nas adversidades enfrentadas durante a história da organização, bem como na identidade distinta da organização. Como exemplo desta realidade, Bromley (1998) nos mostra o caso da companhia americana de vendas diretas Amway. Para o autor, tal empresa (tomada como sendo de natureza 'quase sagrada'), imprime sua dominação ideológica sobre seus 'colaboradores' na medida em que 'prega', em reuniões frequentes com seus participantes, um novo modo de vida associado e interessado ao ideário organizacional. Além disso, a empresa realiza uma série de cerimônias e rituais, muitas vezes envolvendo depoimentos de vendedores bem-sucedidos (que, inclusive, 'ostentam' seu sucesso) que oferecem incentivos e conselhos, a fim de reforçar comportamentos de motivação e compromisso dos novos ingressantes. Em uma perspectiva semelhante, Petinelli-Souza, Oliveira e Silva (2015), nos mostram o caso de outra empresa americana de vendas (Mary Kay) que utiliza várias práticas ritualísticas como, por exemplo, momentos de oração no início de reuniões de unidade, celebração da passagem de nível das consultoras, batismo de diretoras, entre outras.

No que diz respeito ao simbolismo da torre da igreja, podemos observar franca semelhança com a moderna torre capitalista. Esta, também dividida em três regiões: o céu (nível estratégico), a terra (nível tático) e o inferno (nível operacional), insere-se no centro das cidades modernas (expulsando o 'restante do mundo' para a periferia), constituindo-se como lócus principal da vida moderna. Não seria estranho, aqui, portanto, relacionar as condições de trabalho do chão de fábrica da maior parte das indústrias, onde se verifica calor excessivo, ritmo de trabalho extenuante, umidade, a uma cena do inferno de Dante em contraposição ao arcondicionado e purificado dos escritórios presente no topo das torres empresariais.

Esta separação de natureza espacial, inserida no âmbito das organizações, denotaria, ainda, a diferenciação que Bourdieu (2013) faz entre 'efeito de clube' e 'efeito de gueto'. Para o autor, o 'efeito de clube resultaria:

[...] do ajuntamento durável, no interior do mesmo espaço [...] , de pessoas e coisas que se assemelham naquilo em que são diferentes da grande maioria, no fato de terem em comum o fato de não serem comuns -, na medida em que excluem juridicamente [...] ou de fato (estando o intruso condenado a uma espécie de exclusão interior própria a privá-lo de alguns dos lucros de pertencimento) todos aqueles que não apresentam todas as propriedades desejadas, ou que apresentam (ao menos) uma das propriedades indesejáveis (BOURDIEU, 2013, p. 140).

Ainda segundo o autor, o 'efeito de gueto' teria um efeito exatamente inverso ao primeiro. 
[...] o gueto degrada simbolicamente seus habitantes, ajuntando em uma espécie de reserva um conjunto de agentes que, estando privados de todos os trunfos necessários para participar dos diferentes jogos sociais, só partilham de sua comum excomunicação. Além do efeito de estigmatização, o ajuntamento, em um mesmo lugar, de uma população homogênea na despossessão tem também por efeito redobrar a despossessão [...] (BOURDIEU, 2013, p. 140).

Outro ponto importante diz respeito ao fato de que o capitalismo contemporâneo busca atingir metaforicamente o céu a partir de edifícios cada vez mais altos. Instala-se, aí, também, uma lógica de competição das empresas pela construção de 'templos' maiores, mais altos e mais bonitos. A moderna empresa capitalista transforma-se, assim, no elemento central figurativo da cidade contemporânea, uma vez que, quando chegamos a determinadas localidades, observamos de longe seus altos prédios comerciais em detrimento das outras construções. Revela-se simbolicamente, desta maneira, uma posição de submissão das outras dimensões da vida social (religiosa, familiar, política, entre outras) a uma dimensão econômica, realidade tão presente nas sociedades atuais.

Neste sentido, Bourdieu (2013) nos mostra que:

[...] a inscrição imperceptível, nos corpos, das estruturas da ordem social ocorre certamente, em grande parte, através dos deslocamentos e dos movimentos do corpo, das poses e das posturas corporais que essas estruturas sociais convertidas em estruturas espaciais organizam e qualificam socialmente como ascenção ou declínio, entrada (inclusão) ou saída (exclusão), aproximação ou distanciamento em relação a um lugar central e valorizado [...] (BOURDIEU, 2013, p.134-135).

O autor nos apresenta a ideia do espaço (espaço apropriado) como um locus onde o poder se afirmaria e seria exercido de maneira sutil. Dito de outra forma, o poder exercido através de uma violência despercebida, de natureza simbólica. Em uma perspectiva complementar, Lefebvre (1991) argumenta que a sociedade seria um espaço e uma arquitetura de conceitos, formas e leis cujas verdades abstratas seriam impostas na realidade dos sentidos, dos corpos e dos desejos.

Esta percepção do espaço enquanto materialização das relações de poder é, de acordo com Taylor e Spicer (2007), um elemento central na análise das organizações na perspectiva de diversos teóricos da área de estudos organizacionais (WAPSHOTT; MALLETT, 2011; WATKINS, 2005). Em um outro extremo, o autor aponta, ainda, o uso 'desviante' do espaço como uma forma de contestação da realidade dominante como, por exemplo, no uso 'criativo' de portas de banheiro, bem como no rearranjo de móveis no escritório.

O processo de escalada ou ascensão, símbolo da busca de uma realidade absoluta, presente no universo religioso, poderia ser metaforizado, a nosso ver, pela figura da busca de ascensão profissional ou, ainda, pela compreensão da carreira enquanto um 'chamado' (HALL; CHANDLER, 2005). Busca-se, na moderna empresa capitalista, não somente os postos mais altos nas hierarquias, mas, também, os escritórios mais altos nestas torres ('verdadeiras máquinas de trabalhar') que proporcionariam uma visão quase panóptica da realidade social. Os 'vencedores' desta disputa pelos postos mais altos na hierarquia organizacional passariam a ser vistos, assim, pelos subordinados, enquanto detentores de qualidades aparentemente não-humanas, passando a ser objeto de acurada curiosidade, fascinação e, até mesmo, inveja. Conforme nos mostra Gabriel (1997), a separação física e psicológica dos líderes em relação aos 
demais funcionários, somente rompida em ocasiões cerimoniais, teria, como um de seus efeitos, um certo processo de 'criação fantasiosa' acerca das reais características dos primeiros, tornando-os 'quase-deuses'.

Da mesma forma que as portas da igreja guardam o limiar entre o espaço sagrado (interior) e o espaço profano (exterior), as portas da empresa guardariam aquilo que é de propriedade do capital dos olhos e do desejo dos 'outros' (concorrentes, consumidores etc.). A entrada em seus portões somente é feita por meio de convite expresso. Diferentemente do templo religioso que acolhe e abre as portas àqueles que desejam seus mistérios, a empresa guarda suas entradas com vigias, câmeras e crachás.

Aqueles que desejam entrar em seus domínios como trabalhadores, sentem, logo de início, que a sacralidade de seus corpos e de suas almas devem ser abandonadas fora dos portões das fábricas como uma metáfora moderna do inferno de Dante, onde a placa dizia "ao entrar, perca todas as esperanças". Doutrinados em treinamentos corporativos (tanto no processo de entrada quanto durante sua jornada no interior da organização), plenos de um novo discurso ideológico que privilegia uma racionalidade instrumental (lucro e eficiência produtiva, principalmente) em detrimento de uma substantiva, os empregados são instados a ocupar pequenos espaços funcionais (pequenos gabinetes, carinhosamente nomeados enquanto 'baias' ou, até mesmo, postos de trabalho em uma linha de produção) e viver parte de sua vida diária obedecendo normas, regulamentos e processos, algumas das vezes contrários a suas próprias convicções religiosas, políticas e morais. Tais normas, pretensamente objetivas e apolíticas, uma vez que a moderna empresa capitalista insiste em afirmar-se enquanto laica, guardariam semelhanças com os antigos regulamentos religiosos.

É interessante notar que este caráter 'ritualístico' dos processos de socialização de novos membros e treinamento e desenvolvimento de novos gerentes é destacado por diversos autores da área de estudos organizacionais (KAMOCHE, 2000; ACKERS; PRESTON, 1997; GABRIEL, 1997). Ackers e Preston (1997) apontam, por exemplo, um caráter religioso ou quase-religioso nos processos de 'conversão/iluminação' de novos gerentes no decorrer de atividades de treinamento e desenvolvimento no âmbito das empresas modernas. Utilizando-se da noção cristã de conversão, os autores demonstram o caráter transformacional deste tipo de atividade comparando-as aos antigos rituais de passagem e suas três bem conhecidas fases (separação, transição e incorporação). Lee (1992) aponta, ainda, que os rituais de treinamento e desenvolvimento de gerentes teriam, ainda, um caráter muito mais 'sacralizante' do que, propriamente, capacitador de novas competências funcionais.

Vivendo um tempo ordinário, linear, ditado pelo "tic-tac" dos relógios de ponto que controlam seus momentos de entrada e saída da organização, os trabalhadores logo percebem que suas vidas são constantemente vigiadas ou por seus superiores ou pelos próprios processos de trabalho presentes na empresa. Esta vigilância que, em alguns casos, ultrapassa o limite do aceitável (como nos casos de assédio moral, por exemplo), impõe uma lógica de insegurança, pressão e, por que não dizer, de sofrimento, ao trabalhador. $\mathrm{O}$ trabalho, antes visto como fonte de prazer e realização para o ser humano, passa a ser, cada vez mais, dessacralizado e tornado profano nesta nova lógica instaurada no plano organizacional. Esta noção de um Deus vigilante, que observa tudo e todos remeteriam, ainda, à própria ideia de pecado enquanto um elemento de transgressão das regras e preceitos religiosos normalmente aceitos. 'Peca-se' na moderna empresa, na medida em que as metas não são atingidas, o comprometimento com a organização não é pleno, dentre outras tantas possibilidades. 
Esta vida ordinária (incrementada pelo 'aprisionamento' em pequenos espaços funcionais) somente parece ser rompida no momento em que esta cadência interminável e linear de pequenas atividades dá espaço para as pequenas encenações da existência humana. O microcosmo do 'cubículo', em uma tentativa de humanizar tal espaço, é adornado com uma série de elementos simbólicos, dentre os quais destacamos, aqui, aqueles de natureza religiosa ou sagrada. São pequenas estátuas de santos, crucifixos, flâmulas, velas, bíblias, que trazem o universo do sagrado para um espaço (empresa) pretensamente laico/profano. Tal prática, que em algumas empresas é, inclusive, combatida, sobrevive nos cantos das gavetas ou nos bolsos das camisas. Aliado a estas pequenas hierofanias cotidianas, são realizados pequenos gestos, ritos e rituais que trazem o elemento mágico-religioso-sagrado para dentro das organizações empresariais. O sinal da cruz realizado antes de uma reunião importante ou a prece que antecede a um pedido de aumento salarial são pequenas manifestações de que o ser organizacional é, inclusive, um ser religioso e que não há como separar sua natureza social no momento em que o mesmo adentra a empresa. Por isto, conforme afirmamos acima, é possível imaginar que o(s) espaço(s) organizacional(is) é continuamente significado e ressignificado por seus trabalhadores ao longo de sua jornada e que os diversos símbolos presentes nestes espaços, bem como as liturgias associadas aos mesmos, mudam constantemente tornando-o mais ou menos sagrado. É claro que tal realidade somente pode ser observada em um contínuo onde em um extremo poderíamos imaginar uma empresa totalmente laica (não existente na realidade, conforme vimos) e, em outro, uma organização fortemente impregnada do sagrado (uma igreja, por exemplo).

O rompimento com a vida ordinária (profana) no interior das organizações pode ser efetivado, ainda, através de rupturas temporais. Neste ponto, observamos as diversas micropausas no espaço do trabalho (café, conversas informais, etc.) que buscam, essencialmente, inserir o elemento humano em um contexto 'puramente' profano. Há que se destacar, ainda, as diversas festividades que emergem no interior destas organizações, que rompem a lógica da passagem linear do tempo (tempo profano) e inserem um elemento sagrado, instaurando o momento do excesso, da comilança, dos sentimentos aflorados, pelas lágrimas no espaço organizacional. Como exemplos de tais festividades podemos observar as comemorações de aniversário, festas de natal, entre outros. Cumpre destacar, no entanto, que estes pequenos 'espetáculos' são carregados de um universo simbólico e ritualístico que pode adquirir, em determinados momentos, uma função questionadora do status quo, da própria cultura e do próprio cotidiano. Ao sair de seu trabalho, tendo recebido seu 'dízimo', pago todos os dias em pequenas gotas de labuta, o trabalhador encontra o prazer profano fora do espaço organizacional. Encontra-o, finalmente, nas ruas por onde passa, nos bares onde senta ou no sofá de sua casa.

Estes últimos apontamentos nos remetem ao que Taylor e Spicer (2007) denotam como perspectiva do 'espaço como experiência vivida'. De acordo com os autores, esta perspectiva, presente na área de estudos organizacionais, parte da ideia de como os espaços são produzidos e manifestam as experiências daqueles que as habitam. Tendo como ponto de partida análises de natureza linguística e cultural, esta perspectiva organizacional do espaço tende a examinar os aspectos simbólicos inseridos e geridos pelas empresas. Assim, o 'dia-a-dia organizacional', bem como seus múltiplos objetos, seriam carregados de significado simbólico e estético. 


\section{CONSIDERAÇÕES FINAIS}

Este ensaio teórico teve, como objetivo, a compreensão de algumas das possibilidades de interlocução entre os conceitos do sagrado e do profano, especialmente no que tange as suas dimensões espacial e temporal, no universo das organizações empresariais modernas. Partindo, especialmente, das contribuições de Eliade $(2002,2008)$, o texto buscou demonstrar que tais conceitos podem ser interpretados à luz da área de estudos organizacionais, ampliando, assim, sua miríade de conceitos.

Tomando por base a ideia de que a moderna empresa capitalista se instaurou como elemento central em nossa sociedade, assumindo um papel antes restrito as instituições religiosas e que o trabalho (e o homem contemporâneo) foi esvaziado de seu conteúdo sacralizado, o texto aponta para uma série de reflexões que buscam encontrar resquícios do sagrado em um espaço pretensamente laico.

Conforme pudemos observar, os novos formatos organizacionais, presentes na contemporaneidade, parecem caminhar em direção a uma 'nova' e 'ressignificada' ideologia de exploração do capital sobre o trabalho que têm, como inspiração, elementos de natureza religiosa. Tal ideologia, amplamente disseminada através dos manuais organizacionais, bem como pela aplicação de um conjunto de práticas rituais, parece conformar o trabalhador a uma nova lógica de adesão, violentando, simbolicamente, sua subjetividade. A este aprendizado, de natureza 'quase religiosa', segue-se um processo de 'despossessão' e domesticação do corpo do trabalhador que expõe, claramente, a ideia do espaço organizacional (sacralizado) como sendo, essencialmente, espaço de materialização do poder. O espaço do vivido passa a ser visto, somente, nas pequenas manifestações do trabalhador (pequenos gestos, ritos, rituais, adornamentos) no microcosmo do exercício do trabalho, bem como nas pequenas 'encenações' (festas) que surgem ao longo de sua vida na empresa.

Dentre as diversas possibilidades de pesquisas teórico-empíricas derivadas das constatações acima empreendidas, destacamos aquelas relacionadas a ideia de como as dimensões do sagrado e do profano, em suas dimensões espacial e temporal, são (res)significadas, praticamente, pelos diversos participantes das empresas, bem como tais elementos influenciam nas práticas do dia-a-dia. Além disto, convêm destacar as múltiplas possibilidades de estudo do universo ritualístico, ideológico e do discurso presente nas organizações modernas, especialmente no tocante a suas aproximações com o campo religioso.

Em relação as limitações presentes no corpo deste ensaio teórico, destacamos, principalmente, a não-utilização de outros autores da área da sociologia da religião que poderiam, em grande parte, engrandecer a análise efetuada. A escolha por Eliade $(2002,2008)$ deveu-se, basicamente, à profundidade com que o autor polonês trata das categorias do sagrado e do profano em múltiplos contextos sócio-históricos, fato que justifica a transposição de seus argumentos à análise organizacional. Não obstante, esperamos que as discussões aqui apresentadas sirvam de fundamento para o fomento de novos questionamentos sobre a relação entre organizações e religião, abrindo novas possibilidades de pesquisas voltadas para a exploração dessa temática desafiadora no âmbito dos estudos organizacionais, sobretudo no Brasil. 


\section{REFERÊNCIAS}

ACKERS, P.; PRESTON, D. Born again? The ethics and efficacy of the conversion experience in contemporary management development. Journal of Management Studies, v. 34, n. 5, p. 677-701, set. 1997.

ASHFORTH, B .E.; VAIDYANATH, D. Work organizations as secular religions. Journal of Management Inquiry, v. $11, \mathrm{n}$. 04, p. 359-370, dez. 2002.

BERGER, P. L. O dossel sagrado: elementos para uma teoria sociológica da religião. 5 ed. São Paulo: Paulus, 2004.

BOURDIEU, P. Sociólogos da crença e crenças de sociólogos. In: BOURDIEU, P. Coisas Ditas. São Paulo: Brasiliense, 1994. p. 108-113.

BOURDIEU, P. A economia das trocas simbólicas. 6.ed. São Paulo: Perspectiva, 2005.

BOURDIEU, P. O poder simbólico. 11 ed. Rio de Janeiro: Bertrand, 2007.

BOURDIEU, P. A produção da crença: contribuição para uma economia dos bens simbólicos. 3.ed. Porto Alegre: Zouk, 2008.

BOURDIEU, P. Razões práticas: sobre a teoria da ação. 10.ed. Campinas: Papirus, 2010.

BOURDIEU, P. Espaço físico, espaço social e espaço físico apropriado. Estudos Avançados, v. 27, n. 79, p. 133-144, 2013.

BROMLEY, D. G. Transformative movements and quasi-religious corporations: the case of Amway. In. DEMERATH, P.D.; HALL, T.S.; WILLIAMS, R.H. (Orgs.). Sacred companies: organizational aspects of religion and religious aspects of organizations. New York: Oxford University Press, 1998.

CALLOIS, R. O homem e o sagrado. Lisboa: Edições 70, 1989.

CERTEAU, M. de. A Invenção do Cotidiano - Artes do Fazer. 6.ed. Petrópolis: Vozes, 2001.

DODD, S. D; GOTSIS, G. The interrelationships between entrepreneurship and religion. The International Journal of Entrepreneurship and Innovation, v.8, n.2, p.93-104, 2007.

DURKHEIM, E. As formas elementares da vida religiosa. São Paulo: Martins Fontes, 1996.

DUVIGNAUD, J. Festas e civilizações. Rio de Janeiro: Tempo Brasileiro, 1983.

ELIADE, M. Imagens e símbolos: ensaio sobre o simbolismo mágico-religioso. São Paulo: Martins Fontes, 2002.

ELIADE, M. O sagrado e o profano: a essência das religiões. São Paulo: Martins Fontes, 2008.

HALL, D.T.; CHANDLER, D.E. Psychological success: when the career is a calling. Journal of Organizational Behavior, v. 26, n. 2 , p. $155-176$, mar. 2005

GABRIEL, Y. Meeting God: when organizational members come face to face with the supreme leader. Human Relations, v. 50 , n. 4 , p.315-342, abr. 1997.

GALBRAITH, J. K. The age of uncertainty. London: BBC/Andre Deutsch, 1977.

KAMOCHE, K. Developing managers: the functional, the symbolic, the sacred and the profane. Organization Studies, v. 21, n. 4, p. 747-774, jul. 2000.

LEES, S. Ten faces of management development. Management education and development, v, 23, n. 2, p. 89-105, 1992.

LEFEVBRE, H. The production of space. Oxford: Blackwell, 1991.

MAIA, J.; LATTANZI, A. Territórios de criatividade. In: ENCONTRO DA COMPÔS, 16., 2007, Curitiba. Anais... Curitiba: COMPOS, 2007.

PAGĖS, M.; BONETTI, M.; GAULEJAC, V.; DESCENDRE, D. O poder das organizações. São Paulo: Atlas, 2008.

PERNIOLA, M. Mais-que-sagrado - Mais-que-profano. In: BULHÕES, M. A.; KERN, M. L. B. (Orgs). As questões do sagrado na arte contemporânea da América Latina. Porto Alegre: UFGRS-PPGAV, 1997. p. 66-77.

PETINELLI-SOUZA, S.; OLIVEIRA, M. E. C.; SILVA, P.O.M. A produção de discursos em uma empresa de cosméticos: um sonho rosa. FAROL - Revista de Estudos Organizacionais e Sociedade, v. 1, n. 3, p. 10-67, abr. 2015.

SANCHIS, P. Desencanto e formas contemporâneas do religioso. Ciências Sociales y Religion/Ciências Sociais e Religião, v. 3, n. 3, p.27-43, 2001.

SCOTT, T. ; SPICER, A. Time for space: a narrative review of research on organizational spaces. International Journal of Management Reviews, v. 09, n. 4, p. 325-346, 2007.

TEIXEIRA, F. Sociologia da religião: enfoques teóricos (Org.). 3.ed. Petrópolis: Editora Vozes, 2010. 
TRACEY, P. Religion and organization: a critical review of current trends and future directions. The Academy of Management Annals, v. 6, n. 1, p. 55-79, 2012.

TRACEY, P.; PHILLIPS, N.; LOUNSBURY, M. Taking religion seriously in the study of organizations. In: TRACEY, P.; PHILLIPS, N.; LOUNSBURY. (Orgs). Religion and organization theory. London: Emerald, 2014.

WAPSHOTT, R.; MALLETT, O. The spatial implications of homeworking: a Lefebvrian approach to the rewards and challenges of home-based work. Organization, v. 19, n. 1, p. 63-79, 2011.

WATKINS, C. Representations of space, spatial practices and spaces of representation: an application of Lefebvre's Spatial Triad. Culture and Organization, v. 11, n. 3 p. 209-220, set. 2005.

WEBER, M. Economia e sociedade: fundamentos da sociologia compreensiva. 3.ed. Brasília: UNB, 2000.

WEBER, M. A ética protestante e o espírito do capitalismo. São Paulo: Pioneira, 2001.

WEBER, M. Sociologia das religiões. Lisboa: Antropos, 2006. 